Original Contribution

\title{
DIAGNOSTIC EFFICIENCY OF SERUM CREATINE KINASE AND TROPONIN I IN PATIENTS WITH SUSPECTED ACUTE MYOCARDIAL INFARCTION
}

\author{
S. A. Zrari ${ }^{1}$, S. K. Mohammed ${ }^{2}$ \\ ${ }^{1}$ Department of Clinical Biochemistry - College of Medicine, Hawler Medical University, Erbil, Iraq \\ ${ }^{2}$ Department of Clinical Biochemistry - College of Health Sciences, Erbil, Iraq
}

\begin{abstract}
A myocardial infarction is the irreversible necrosis of heart muscle secondary to prolonged ischemia, that occurs when a portion of the heart is deprived of oxygen due to rupture of a vulnerable plaque of a coronary artery.

The present study was undertaken to evaluate the usefulness of serum troponin I and Creatine kinase-MB in the clinical diagnosis of patients with suspected acute myocardial infraction through the chemical eye. This prospective study was carried out during the period from 2013 to 2015 on fifty patients with myocardial infarction and the results obtained were compared with thirty normal subjects. Serum Troponin I and Creatine kinase-MB were measured by Enzyme-Linked Immunosorbent Assay.

The results revealed that the levels of serum Troponin I and Creatine kinase-MB activity in patients with myocardial infraction were significantly higher $(\mathrm{P}<0.01)$ compared with normal healthy subjects. In addition, according to our data a strong correlation can be observed between Troponin I and Creatine kinase MB.

In the frame of this work we investigated that the myocardial infarction had significant effect on serum Troponin I and Creatine kinase-MB, consequently, these biochemical parameters together may be useful as an additional follow up tools in those with suspected acute myocardial infraction.
\end{abstract}

Key words: Myocardial infarction, Troponin I, Creatine kinase, lipid and lipoprotein profiles.

\section{INTRODUCTION}

Acute myocardial infarction (AMI or MI), more commonly known as a heart attack occurs when there is a sudden cessation of blood flow following a thrombotic occlusion of a coronary artery previously narrowed by atherosclerosis. (1)

Coronary arteries supply the heart muscle (myocardium) with oxygenated blood. Without oxygen, muscle cells served by the blocked artery begin to irreversible necrosis of heart muscle and potential death of heart tissue (Infarct). Slowly developing, High grade coronary artery stenosis usually does not precipitate acute infarction because of the development of a rich collateral network over time. Infarction occurs when a coronary artery thrombus develops rapidly at a site of vascular injury (when the atherosclerotic plaque

\footnotetext{
* Correspondence to: Asst. Prof. Dr. Salar A. Zrari, Department of Clinical BiochemistryCollege of Medicine - Hawler Medical University, Erbil, Kurdistan region of Iraq, Tel: 009647504101917, E-mail: salarzrari@yahoo.com
}

fissures, ruptures, or ulcerates). It usually occurs in persons with risk factors for atherosclerosis (2).

It is well-known that nowadays myocardial infarction is one of the most important mortality factors according to the World Health Organization, The frequent MI risk factors including diabetes mellitus, hypertension, smoking, hyperlipidemia, gender and the age, (3) acute myocardial infarction presents with sudden onset severe central chest pain, dyspnea, sweating, pallor and syncope (4).

The extent of myocardial injury is an important predictor of outcome in patients with myocardial infarction,5 following acute myocardial infarction, and prognosis is largely related to the extent of myocardial necrosis and the resultant decline in left ventricular function (6).

According to the contemporary universal definition of MI, the criteria for diagnosis of acute MI were recommended as follow: 
elevation of cardiac enzymes (7) together with evidence of myocardial ischaemia with at least one of the following: (a) symptoms of ischaemia; (b) history of characteristic chest pain, (c) evolutionary changes of the electrocardiogram (iv) imaging evidence of new loss of viable myocardium or new regional wall motion abnormality (8-10).

Cardiac enzymes are proteins from heart muscle cells that are released into the bloodstream when heart muscle is damaged, such as during a myocardial infarction (MI). By measuring blood levels of cardiac specific enzymes, doctors can tell whether heart muscle damage has recently occurred. Therefore, measuring cardiac enzymes is often an important step in diagnosing MIs (9).

Current clinical practice is to measure different cardiac enzymes when an MI is suspected like creatine kinase $(\mathrm{CK})$, myoglobin and troponin (11).

The troponin complex is located on the thin filament of striated muscle and is composed of three isoforms: troponin $\mathrm{T}$, which attaches the troponin complex to tropomyosin; troponin I (Tn-I), which modulates the interaction of actin and myosin by inhibiting actomyosin adenosine triphosphatase activity; and troponin $\mathrm{C}$, the calcium-binding subunit of the troponin complex. Troponin I \& T has nearly absolute myocardial tissue specificity and high clinical sensitivity $(8,9,12)$.

The measurement of CK level has long been used for the diagnosis of MI, CK, is an enzyme expressed by various tissues and cell types, which catalyses the conversion of creatine and utilizes adenosine triphosphate to create phosphocreatine and adenosine diphosphate (13).

In the cells, the "cytosolic" CK enzymes consist of two subunits, which can be either B (brain type) or $\mathrm{M}$ (muscle type). There are, therefore, three different isoenzymes: CK-MM, CK-BB and CK-MB (14).

Clinically, CK is assayed in blood tests as a marker of damage of CK-rich tissue such as in myocardial infarction (heart attack), rhabdomyolysis (severe muscle breakdown), muscular dystrophy, the autoimmune myositides and in acute renal failure $(15,16)$

The aim of this study was to investigate the link between AMI and Tn-I and CK-MB levels and to evaluate if these biochemical parameters are sensitive and specific biomarkers of AMI.

\section{MATERIAL AND METHODS}

\section{Subjects}

The present study consisted of 80 individuals, 30 of whom were volunteer controls with no clinical evidence of any type of diseases, their mean age was 47, ranging from 30-60 years of age. The remaining 50 individuals were patients with suspected MI admitted to the coronary care unit $(\mathrm{CCU})$ in order to diagnosis and receive treatment, the diagnosis of MI was confirmed within the previous 12 hours of chest pain by clinical and laboratory findings of chest pain, electrocardiogram changes, and elevations of biomarkers indicating cardiac injury their mean age was 49 , ranging from 35 63 years of age.

This work was carried out during the period from April 2014 to January 2015, by collaboration between College of Medicine and Heath Sciences - Clinical biochemistry departments- Hawler Medical University.

\section{Samples}

Three $\mathrm{ml}$ of blood was collected via a traumatic antecubital venipuncture into vacutainer tube in the morning after overnight fasting from each subject. The serum was recovered by centrifugation at $3000 \mathrm{rpm}$ for 15 minutes. The samples were either used immediately for estimation of serum Tn-I, CK$\mathrm{MB}$, lipid and lipoprotein profiles or kept at about $20^{\circ} \mathrm{C}$ until further analysis.

\section{Methods}

\section{A- Determination of serum CK-MB :}

The ELISA test (AccuDiag ${ }^{\mathrm{TM}}$ CK-MB ELISA Kit- Woodland Hills, California, USA ) for CK-MB is based on the principle of a solid phase enzyme-linked immunosorbent assay (17). The assay system utilizes a monoclonal antibody directed against a distinct antigenic determinant on the CK-MB molecule. A goat anti-CK-MB antibody conjugated to horseradish peroxidase is in the antibody enzyme conjugate solution. After 1 hour incubation at room temperature, the wells are washed with water. A solution of TMB Reagent is added and incubated at room temperature for 20 minutes, resulting in the development of a blue color. The color development is stopped with the addition of Stop Solution changing the color to yellow. The color intensity is measured spectrophotometrically at $450 \mathrm{~nm}$.

\section{B- Determination of serum cardiac Tn-I:}

The cTnI- ELISA test (RapiCard ${ }^{\mathrm{TM}}$ InstaTest Troponin I kit - Woodland Hills, California, USA) is based on the principle of a solid phase enzyme-linked immunosorbent assay 
(18) Three mouse monoclonal anti-troponin I antibodies are used for solid phase immobilization. The fourth antibody is in the antibody-enzyme (horseradish peroxidase) conjugate solution. The test sample is allowed to react simultaneously with the four antibodies, after 90-minute incubation at room temperature, a solution of tetra methyl benzidine reagent is added and incubated for 20 minutes, resulting in the development of a blue color. The color development is stopped with the addition of $1 \mathrm{~N}$ hydrochloric acid changing the color to yellow, then the intensity of the color measured spectrophotometrically at $450 \mathrm{~nm}$.

\section{C- Determination of serum lipid and lipoprotein profiles:}

Serum lipid and lipoprotein profiles were determined for both groups spectrophotometrically by using Biomerieux $\mathrm{Sa}$ Commercial diagnostic kits (France). Fasting serum total cholesterol (TC), and HDL-C were measured according to the method of Trinder,(19) Fasting serum triacyl glycerol (TAG) was determined by a method described by Young and Destany,(20) while serum fasting LDL-C and VLDL-C were calculated according to Friedewald equation.(21)

\section{Statistical analysis:}

Data were evaluated by SPSS software (SPSS Inc. Chicago, IL, USA). Values are reported as mean $\pm \mathrm{SE}$, the correlation coefficient $\left(\mathrm{r}^{2}\right)$ was used to assess the link between Tn-I and CKMB levels. T-test for independent samples was employed to find out the statistical significance. The levels of serum Tn-I, CK$\mathrm{MB}$, lipid and lipoproteins profile of normal healthy subjects were compared with that of suspected patients with MI concerning P value; statistical significance was set at $(\mathrm{P}<0.05)$ (22).

\section{RESULTS}

\section{Group I (Control group):}

The mean \pm S.E level for serum Tn-I and CK$\mathrm{MB}$ were $0.02 \pm 0.01$ and $3.7 \pm 0.05 \mathrm{ng} / \mathrm{ml}$, respectively. The mean \pm S.E values for fasting serum TG and TC were $127 \pm 1.8$ and $175 \pm 2.5 \mathrm{mg} / \mathrm{dl}$, respectively. While the respective mean \pm S.E of fasting serum lipoproteins (HDL-C, LDL-C and VLDL-C) were $65 \pm 1.4,101 \pm 0.7$ and $20 \pm 0.1 \mathrm{mg} / \mathrm{dl}$, respectively, The results of the present study are depicted in Table 1.

\section{Group II (Patients with MI):}

The laboratory parameters of patients with MI are shown in Table (1). The mean \pm S.E level for serum Tn-I and CK-MB were $20.12 \pm 0.03$ and $128 \pm 1.1 \mathrm{ng} / \mathrm{ml}$, respectively. The mean \pm S.E values for fasting serum TG and TC were $227 \pm 1.9$ and $279 \pm 2.4 \mathrm{mg} / \mathrm{dl}$, respectively.

While the mean \pm S.E values for fasting serum lipoproteins (HDL-C, LDL-C and VLDL-C) were $32 \pm 0.1,188 \pm 0.3$ and $49 \pm 0.9 \mathrm{mg} / \mathrm{dl}$, respectively,

The data analysis indicated statistically significant increased $(\mathrm{P}<0.01)$ in mean concentrations of Tn-I (1006 times upper normal range), CK-MB (34.6 times upper normal range), TC, TG, LDL-C and VLDL-C were observed in sera of patients with $\mathrm{MI}$ in comparison with normal healthy subjects, whereas the levels of HDL-C, decreased in a statistically significant manner $\quad(\mathrm{P}<0.01)$, (Table 1).

Figure 1 shows the correlation coefficient between serum Tn-I and CK-MB, According to our data a satisfactory correlation $\left(\mathrm{r}^{2}=8.27\right)$ can be observed between Tn-I and CK-MB serum samples.

Table 1. Details of biochemical parameters of the studied groups.

\begin{tabular}{|c|c|c|c|c|c|}
\hline \multirow[b]{2}{*}{$\begin{array}{l}\text { Biochemical } \\
\text { parameters }\end{array}$} & \multicolumn{2}{|c|}{ Group 1} & \multicolumn{2}{|c|}{ Group II } & \multirow{2}{*}{$\begin{array}{c}\text { Statistical } \\
\text { evaluation } \\
\text { P value }\end{array}$} \\
\hline & Range & $\begin{array}{c}\text { (Mean } \pm \\
\text { S.E. })\end{array}$ & Range & $\begin{array}{c}\text { (Mean } \pm \\
\text { S.E.) }\end{array}$ & \\
\hline Tn-I ng/ml & $0-0.12$ & $0.02 \pm 0.01$ & $0.3-63$ & $20.12 \pm 0.03$ & 0.0016 \\
\hline CK-MB ng/ml & $0.1-5.1$ & $3.7 \pm 0.05$ & $30-650$ & $128 \pm 1.1$ & 0.0011 \\
\hline TG mg/dl & $45-202$ & $127 \pm 1.8$ & $154-295$ & $227 \pm 1.9$ & 0.015 \\
\hline TC mg/dl & $110-225$ & $175 \pm 2.5$ & $180-325$ & $279 \pm 2.4$ & 0.011 \\
\hline HDL-C mg/dl & $29-90$ & $65 \pm 1.4$ & $27-81$ & $32 \pm 0.1$ & 0.010 \\
\hline LDL-C mg/dl & $33-190$ & $101 \pm 0.7$ & $137-224$ & $188 \pm 0.3$ & 0.011 \\
\hline VLDL-C mg/dl & $10-42$ & $20 \pm 0.1$ & $30-62$ & $49 \pm 0.9$ & 0.011 \\
\hline
\end{tabular}

\section{DISCUSSION}

Myocardial infarction is the irreversible damage of myocardial tissue caused by prolonged ischemia and hypoxia (23). In the present study, we describe the diagnostic performance characteristics of cardiac Tn-I (cTn-I) and CKMB for AMI.

These data are consistent with and extend findings from previous research that has identified cTnI and CK-MB as markers for myocardial injury. 
ZRARI S. A., et al.

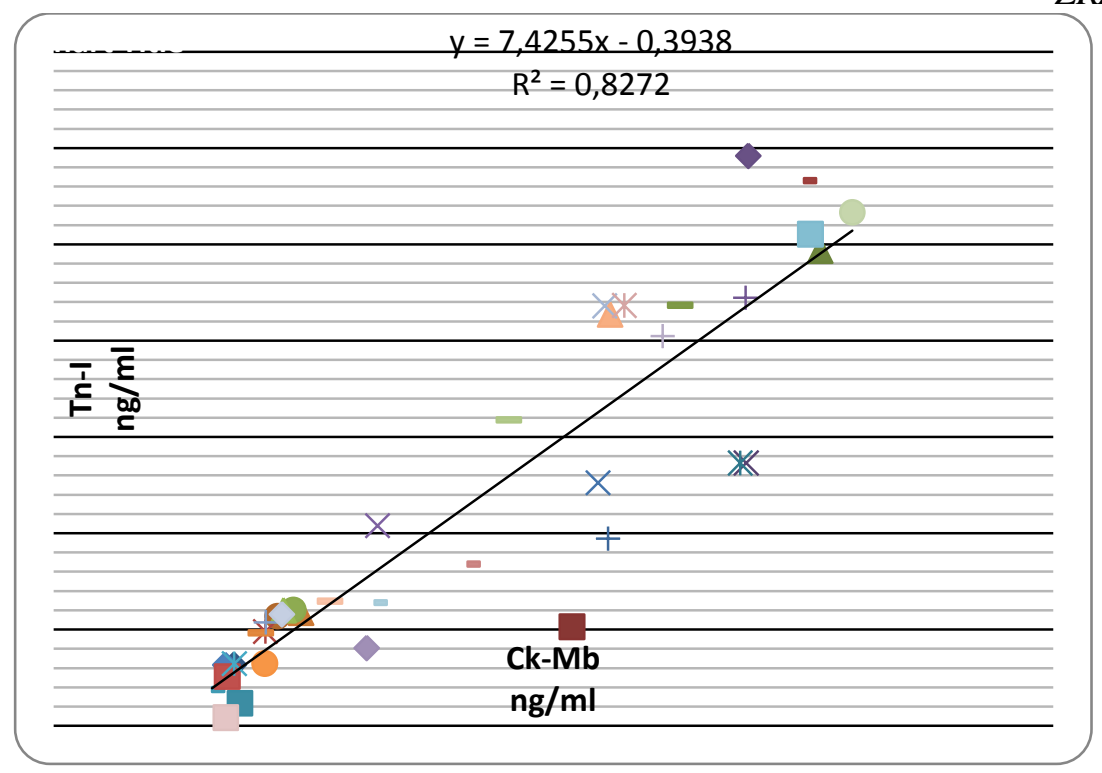

Figure 1. Correlation coefficient between serum $\mathrm{CK}-\mathrm{Mb}$ and $\mathrm{Tn}-\mathrm{I}$.

Our study clearly showed that AMI patients had significantly higher levels of cTnI and CK$\mathrm{MB}$ as compared to the healthy controls. Hence cTnI is more specific for confirming the diagnosis of acute MI, with elevations of CK$\mathrm{MB}$, indicating severe myocardial cell injury. According to our data a strong correlation can be observed between cTn I and CK-MB in serum samples of healthy individuals

The results on serum cTnI and CK-MB activity in present study were in accordance with the reports from other workers (24-27).

The mechanism responsible for an increase in serum CK-MB and cTnI activity in MI patients is due to necrosis of myocardial cells, a myocardial infarction, commonly known as a heart attack, occurs when a portion of the heart is deprived of oxygen due to blockage of a Coronary arteries supply the myocardium with oxygenated blood. Without oxygen, muscle cells served by the blocked artery begin to die (infarct) (17).

Creatine kinase and Tn-I are two intracellular enzymes present in greatest amounts in, myocardium, disruption of cell membranes due to hypoxia or other injury releases $\mathrm{CK}$ and Tn-I from the cellular cytosol into the systemic circulation. On this basis, elevated serum levels of CK-MB and Tn-I have been used as a sensitive test for MI (18).

On the other hand the mean values obtained for AMI patients for fasting serum TC, TAG, VLDL-C and LDL-C were significantly higher than those of healthy controls $(p<0.01)$ This finding were in agreement with those obtained by other investigators, (28-30) The mechanism responsible for an increase in serum lipids
(TG , TC, VLDL-C and LDL-C) in AMI patients may be due to elevated flux of fatty acids and impaired removal of VLDL from the plasma (19). Furthermore, high Concentration of apoprotein B in survivors of AMI may lead to accumulation of chylomicron remnants, VLDL-C and IDL-C. Since most of cholesterol in the plasma is carried by LDL, an increase in LDL level directly may lead to an increase in TC levels as well (20).

Elevated plasma LDL level may be due to over production or decrease its clearance as a result of modifying and blocking of LDLreceptors located on the cell surface, a decrease in LDL receptors activity leads to reduced cellular uptake of serum LDL-C (21).

Whereas the mean value obtained for AMI patients for fasting serum HDL-C was significantly lower that of control group. Similar results have also been reported by other workers $(27,28,30,31)$.

The mechanisms responsible for this change may reside in the decreased synthesis and secretion of HDL-C from the liver or intestine and/ or accelerated elimination from the blood stream by extravasations. Increased permeability of the capillary membranes during the acute inflammation after AMI lead also to an extravasation of HDL-C. Furthermore, decreased level of apoprotein A affects directly the HDL-C level (32).

\section{CONCLUSION}

The present study does not support the routine use of cTn-I as a diagnostic tool, the test showed a significantly better performance cTnI and CK-MB together for predicting major cardiac events among patients who were ruled 
out for myocardial infarction. The presence of abnormal cTn-I and CK-MB levels supports the need for intensive patient evaluation and monitoring.

\section{REFERENCES}

1. Davies, MJ., The birth, growth, and consequences of the atherosclerotic plaque. Dialog Cardiovasc Med, 4 (3): 115-30, 1999.

2. DeWood, M.A. Spores, J. Notske, R. Mouser, LT. Burroughs, R. Golden, MS. et al., Prevalence of total coronary artery occlusion during the early hours of transmural myocardial infarction. $N$ Eng $J$ Med, 303: 890-7, 1980.

3. Csaba T., Echocardiographic experiences and clinical observations in acute myocardial infarction. $\mathrm{PhD}$ Thesis. Debrecen: University of Debrecen; 2002.

4. Antman, E. Bassam, JP. Klein, W. Ohman, M. Sendon, JLL. Ryden, L. et al., For the Joint European Society of Cardiology/American College of Cardiology Committee for the redefinition of Myocardial Infarction. $J$ Am Coll Cardiol, 36: 959-69, 2000.

5. Tomasz, R. Artur, D. Jacek, L. Pawel, K. Agata, B. Zbigniew, S. et al., Creatine Kinase-MB assessed in patients with acute myocardial infarction correlates with cardiac magnetic resonance infarct size at 6-month follow up. Hellenic J Cardiol, 55: 4-8, 2014.

6. Shokoufeh, H. Mitra, C. Mandana, C. Majid, H. Nima, B. Zahra, N. et al., Metabolic syndrome is associated with higher wall motion score and larger infarct size after acute myocardial infarction. Res Cardiovasc Med, 4(1): e25018, 2015.

7. Terry, W. Gary, K. Lynn, S., Differences of creatine kinase-MB and cardiac troponin-I concentrations in normal and diseased human myocardium. Ann Clin Lab Sci, 32(1): 44-8, 2002.

8. Braunwald, E. Antman, EM. Breasley, JW. Califf, RM. Cheitlin, MD. Hochman, JS. et al., ACC/AHA guidelines for the management of patients with unstable angina and non-ST-segment elevation Myocardial Infarction. J Am Coll Cardiol, 36: 970-1062, 2000.

9. Iraj, M. and Esmail, R. Salivary Troponin I as an indicator of myocardial infarction. Indian J Med Res, 138: 861-5, 2013.

10. Mohamad, N. and Bassam, A., Diagnostic efficiency of creatine kinase (CK), CKMB, Troponin $\mathrm{T}$ and Troponin $\mathrm{I}$ in patients with suspected acute myocardial infarction. J Health Sci, 52(2): 180-5, 2006.
11.Kent, L. Ahchean, C. and James, J., Cardiac markers for myocardial infarction. Am J Clin Pathol, 118(1): 93-9,2002.

12.Roger, VL. Killian, JM. Weston, SA. Jaffe, AS. Kors, J. Santrach, PJ. et al., Redefinition of myocardial infarction: prospective evaluation in the community. Circulation, 114: 790-7, 2006.

13.Bong, S. Moon, J. Nam, K. Lee, K. Chi, Y. and Hwang, K., "Structural studies of human brain-type creatine kinase complexed with the ADP- $\mathrm{Mg}^{2+}-\mathrm{NO} 3-$ creatine transition-state analogue complex". FEBS Lett, 582(28): 3959-65, 2008.

14.Moss, D. and Henderson, A. Enzymes. In: C.A. BURTIS and E.R. Ashwood, eds. Tietz textbook of clinical chemistry. Second Edition. Philadelphia. W.B. Saunders Company, 1994.

15.Wallimann, T. Wyss, M. Brdiczka, D. Nicolay, K. and Eppenberger, HM., "Intracellular compartmentation, structure and function of creatine kinase isoenzymes in tissues with high and fluctuating energy demands: the "phosphocreatine circuit" for cellular energy homeostasis". Biochem $J$, 281(1): 21-40, 1992.

16.Wallimann, T. and Hemmer, W., Creatine Kinase in non-muscle tissues and cells. Mol Cell Biochem, 133-135: 193-220, 1994.

17.Kristian, T. Joseph, SA. Allan, SJ. Maarten, LS. Bernard, RC. And Harvey, D., White hird universal definition of myocardial infarction. J Am Coll Cardiol, 126: 2020-35, 2012.

18.Walker, HK. Hall, WD. And Hurst, JW., Clinical Methods- The History, Physical, and Laboratory Examinations. Third Edition. Emory University School of Medicine, Atlanta, Georgia Boston. Butterworths. 1990.

19. Moshides, JS., Enzymatic determination of the free cholesterol fraction of high-density lipoprotein in plasma with use of 2,4,6tribromo-3-hydroxybenzoic acid. Clin Chem, 34(9): 1799-804, 1988.

20. Hargreaves, AD. Logan, RL. Thomson, M., Total cholesterol, LDL-C and HDL-C and coronary Heart Disease. BMJ, 303: 678, 1991.

21.Kromhout, D., Body weight, diet and serum cholesterol in middle aged men during 10 years follow up. Am J Clin Nutr, 38: 591, 1983.

22.Daniel, WW., Biostatistics: A foundation for analysis in the Health Science. $3^{\text {rd }}$ Edition. USA: John Wiley and Sons; 1983.

23.Nigam, PK., Biochemical markers of myocardial injury. Indian J Clin Biochem, 22(1): 10-7, 2007. 
24.Mullner, M. Hirschl, MM, Herkner, $\mathrm{H}$. Sterz, F. Leitha, T. Exner, M. et al., Creatine Kinase-MB fraction and cardiac Troponin $\mathrm{T}$ to diagnose acute myocardial infarction after Cardiopulmonary resuscitation. J Am Coll Cardiol, 28: 12201225, 1996.

25.Zimmerman, J. Fromm, R. Meyer, D. Boudreaux, A. Wun, CC. Smalling, R. et al., Diagnostic marker cooperative study for the diagnosis of myocardial infarction. Circulation, 99: 1671-7, 1999.

26.Prabodh, VS. Chowdary, NV. Reddy, YV. Shekhar, R. and Vidya, D., Lipid profile levels on the second day of acute myocardial infarction. Int J Pharm Bio Sci, 3(3): 245-50, 2012.

27.DeSilva, LDR. Kumar, A. and Sathian, B., The significance of lipid profile and positive Troponin in predicting cardiac event. Kathmandu Univ Med J, 7(3): 263-7, 2009.
28.Nigam, PK. Narain, VS. and Hasan, M., Serum Lipid profile in patients with acute myocardial infarction. Indian $J$ Clin Biochem, 19(1): 67-70, 2004.

29.Sarkar, D. Latif, SA. And Uddin, MM., Studies on serum Lipid profile in hypertensive patients. Mymensingh Med J, 16(1): 70-6.2007.

30.Rathish, R. Gayathri, G. and Sumathi, P., Current Biomarkers for myocardial infarction. Int J Pharm Bio Sci, 4(1): 43442, 2013.

31.Haseeb, AK. Abdullah, SA. And Samia, HS., Lipid profile of patients with acute Myocardial Infarction and its correlation with systemic inflammation. Biomarkers Insight, 8: 1-7, 2013.

32. Tayfoor, JM. Kameran, YM. And Omer, S., Serum Lipid and Lipoprotein Profiles in Patients with Acute Myocardial Infarction. MEJIM, 1(2): 21-4, 2008. 